\title{
Determination of Flux from a Saddle Field Fast-Atom Bombardment Gun
}

\author{
Bill Boggess and Kelsey D. Cook \\ Department of Chemistry, University of Tennessee, Knoxville, Tennessee, USA
}

\begin{abstract}
The flux or beam density (equivalent current/area) of xenon atoms striking the sample target from a saddle field fast-atom bombardment (FAB) gun has been compared with that from a cesium ion gun mounted on the same instrument. A shielded Faraday cup mounted on the end of a solids probe was used to measure directly the flux of the $\mathrm{Cs}^{+}$beam. Samples of methylene blue in glycerol solution were then exposed to the ion beam at different fluxes and the extents of reduction were measured. The extent of reduction varied linearly with flux up to a value of about $1.16 \times 10^{13}$ particles $\mathrm{s}^{-1} \mathrm{~cm}^{-2}\left(1.85 \mu \mathrm{A} \mathrm{cm} \mathrm{cm}^{-2}\right)$; above this level, the reduction effect appeared to saturate. FAB spectra were obtained from the same dye solution hy using varying settings of the $\mathrm{FAB}$ gun. By comparing the extents of reduction of the dye from the two guns, the flux from the atom gun could be estimated. Observation of luminescence from a CsI-coated target allowed estimation of the area of the atom beam. The atom beam "equivalent current" could then be calculated by multiplying the flux times the area. It was noted that for given settings, the flux from the atom gur depended on the physical condition of the gun electrodes. With new electrodes, a flux $\geq 1.16 \times 10^{13}$ particles $\mathrm{s}^{-1} \mathrm{~cm}^{-2}$ was obtained with nominal gun emission currents of $0.60-1.0 \mathrm{~mA}$. Electrodes used extensively, but freshly cleaned, provided a flux of $\sim 8 \times 10^{12}$ particles $\mathrm{s}^{-1} \mathrm{~cm}^{-2}$ at nominal emission currents of $0.40-1.0 \mathrm{~mA}$. With dirty electrodes this flux could orly be achieved at the highest (1.0 mA) emission current. This decline in performance occurs over a matter of months as a result of contamination and erosion of the electrodes during use. Such behavior can adversely affect spectral reproducibility even when nominal FAB gun voltage and emission current are carefully reproduced. (J Am Soc Mass Spectrom 1994, 5, 100-105)
\end{abstract}

$\mathrm{T}$ The advent of fast-atom bombardment (FAB) [1] and liquid secondary ion mass spectrometry (LSIMS) [2, 3] greatly extended the range of compounds amenable to mass spectrometric analysis. In the past decade, these techniques have matured, becoming methods of choice for the mass spectrometric analysis of thermally labile compounds of mass up to perhaps a few thousand daltons. Many phenomenological and theoretical studies have greatly increased our understanding of these desorption methods [4-6]. Important questions remain, however. There is even contention concerning the fundamental issue of whether FAB is a "soft" ionization technique: Williams et al. [7] and Derwa et al. [8] concluded that the internal energy content of desorbed ions is $<3.5 \mathrm{eV}$, a point disputed by Takayama et al. [9].

One point on which there is fairly broad consensus is the potential for complications from artifacts. There have been several reports of beam-induced chemical reactions (reduction, addition, etc.) [4-6]. Efforts to gain an understanding of the dependence of these artifacts on primary beam characteristics have been

Address reprint requests to Kelsey D. Cook, Department of Chemistry, University of Teruessee, Knoxville, TN 37996-1600. impeded by the difficulty of characterizing the neutral primary beam used in FAB. Users of FAB generally list, at most, the nominal primary beam energy and the current drain on the power supply. While the energy of neutral species cannot be readily determined, several reports have shown that the majority $(70 \%)$ of the ions that escape from the gun are singly charged and acquire energies corresponding to $70-85 \%$ of the anode potential $[10,11]$. The relation between current drain and particle flux is even less well characterized. Ligon [10] applied thermodynamic and kinetics calculations to the depletion of glycerol during bombardment to obtain an upper limit estimate of flux. Alexander and Hogg [11] reported a "neutral current equivalent" for several different primary particles (e.g., argon, xenon, mercury, DC705, and Santovac-5) emerging from a saddle field gun. They used a Faraday cup with a suppressor plate to measure both the ionic component of the primary beam and the secondary electron emission current with and without deflection of primary ions. Yields of secondary electrons from the surface of the Faraday cup were assumed to be the same for neutral and ionic primary particles of the same mass and energy. No quantitative information was presented about beam size, so flux (equivalent 
current/area) could not be calculated. Because it is this flux, rather than simply current, which correlates with the extent of beam-induced damage [12-14], it would be useful to have an accurate and simple measure of the primary beam flux at the target. Such a measure would facilitate reproducibility and interlaboratory comparisons of FAB data.

While flux determination is relatively straightforward for ion beams (representing one of the advantages of LSIMS $[2,15]$ ), it is not possible to measure directly the "current" from a neutral beam. In an earlier study, we used secondary ion intensity from a dry CsI sample to calibrate the flux from a FAB gun [13]. However, this approach suffers from uncertainties that can affect absolute secondary ion intensity, such as variations in source geometry and tuning parameters, detector sensitivity, etc. These effects can be reduced or eliminated by relying instead on a flux-sensitive ratio between the intensities of ions of similar mass. This study undertakes evaluation of beam-induced damage in a reference system as an indirect measure of primary flux. As candidates for monitoring beam-induced chemistry, we have examined indoine blue, bradykinin, and met-enkephalin in addition to the dyes listed in ref 13 . Methylene blue reduction was the most sensitive to flux, and will be discussed here. Although we have calibrated flux with a Faraday cup and $\mathrm{a} \mathrm{Cs}{ }^{+}$beam, it is expected that the qualitative calibration should be transferable without the need for any special hardware.

\section{Experimental}

Spectra were obtained with a VG ZAB-EQ mass spectrometer (VG Analytical, Altrincham, UK) operating at a nominal accelerating potential of $8 \mathrm{kV}$. Data were collected with an 11-250 J data system in the selected ion recording mode using voltage jumping $(0.1 \mathrm{~s}$ dwell count, $0.1 \mathrm{~s}$ step time).

The mounting arrangement of the two primary sources used in this study is shown in Figure 1. An Ion Tech (Middlesex, UK) FAB gun using research grade xenon (MG Industries, North Branch, NJ) was operated at $8.0 \mathrm{kV}$. This gun incorporates an electrode $(8.0 \mathrm{kV})$ just beyond the exit aperture to deflect $\mathrm{Xe}^{+}$out of the beam. During the course of this study, the FAB gun electrodes had to be cleaned and ultimately replaced with new ones (VCR Group Inc., South San Francisco, CA). A Phrasor Scientific (Duarte, CA) cesium ion gun was operated at $16.0 \mathrm{kV}$ ( $8.0 \mathrm{kV}$ above source potential) and $10 \mu \mathrm{A}$ emission current. Flux was varied by changing the focus of the primary $\mathrm{Cs}^{+}$beam.

$A$ VG flow-FAB ion source was modified by extending the region between the ion block and the next electrode from $8 \mathrm{~mm}$ to $11 \mathrm{~mm}$; no decrease in performance was noted. This provided an unobstructed path for the $\mathrm{Cs}^{+}$primary ions, allowing the same ion source to be used with both guns. A modified VG solids probe was used [13]. Due to the mounting arrange-

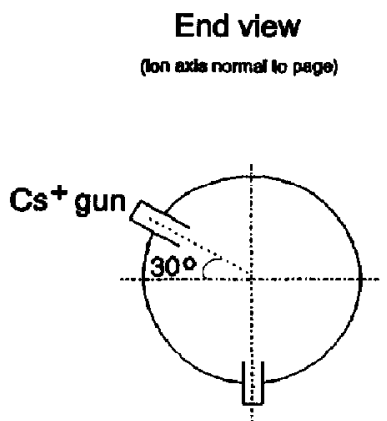

FAB gun

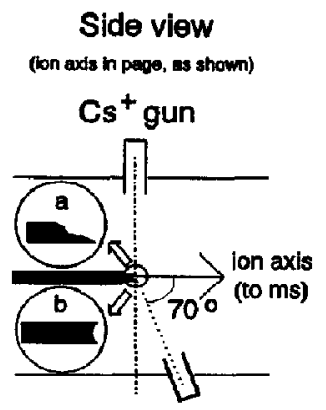

FAB gun
Figure 1. Mounting arrangement of the cesium ion gun and $F A B$ gun on the source housing of the ZAB-EQ. Insets show probe tip profiles for (a) LSIMS and (b) FAB. The probe is parallel, and the $\mathrm{Cs}^{+}$beam is normal, to the ion axis. Drawings are not to scale.

ments, different geometry probe tips had to be used for FAB and LSIMS (see insets $a$ and $b$ in Figure 1). For FAB experiments, a concave depression $(\sim 1 \mathrm{~mm}$ deep) was machined into the flat end of a $1 / 8^{\prime \prime}$ o.d. brass probe tip to permit reproducible sample loadings of 5-20 $\mu \mathrm{L}$. For LSIMS experiments, this was accomplished by machining a concave groove $(\sim 1 \mathrm{~mm}$ deep) across a slanted $\left(30^{\circ}\right)$ probe tip surface. The concave surfaces minimized sample "droop" and problems associated with the poor wettability of the tips by causing the sample droplet to shrink toward the tip center during bombardment. While the probe tip angle affected absolute intensities, ratios (including the enrichment factor described below) were insensitive to this angle.

A shielded Faraday cup (Figure 2) with a $1.0 \mathrm{~mm}$ diameter aperture was attached to a Keithley (Cleveland, $\mathrm{OH})$ Model $600 \mathrm{~A}$ electrometer for primary ion current measurements. Reported fluxes represent the average of measurements made before and after each LSIMS experiment (without adjusting gun parameters). These measurements differed by no more than $5 \%$ with $\pm 2 \%$ being typical.

To estimate the diameter of the FAB atom beam, a flat stainless steel target $(2 \mathrm{~cm} \times 2 \mathrm{~cm})$ marked with 1 $\mathrm{mm}$ grid lines was coated with CsI (reagent grade, Aldrich Chemical Co., Milwaukee, WI). The salt was

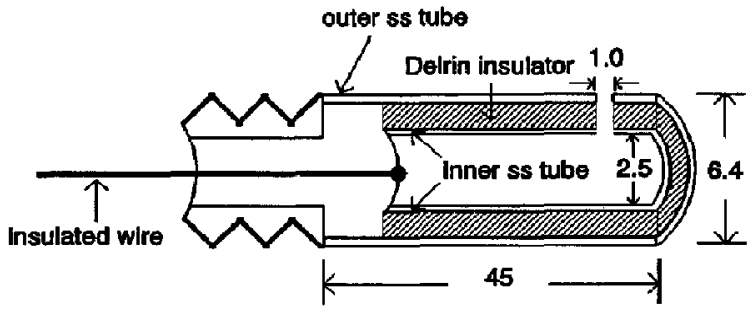

Figure 2. Cross-sectional view of the Faraday cup used to measure flux from the cesium ion gun. Dimensions are in millimeters. 
applied from a saturated methanol (reagent grade, Mallinckrodt, St. Louis, MO) solution and the solvent was allowed to evaporate. The ion source was removed to accommodate the flat target. The coated target was positioned at essentially the same position as that normally occupied by the sample, then illuminated with the primary beam. The diameter of the resulting luminescent spot was determined by counting the grid lines enclosing the bright circular primary beam image.

A $15 \mathrm{mM}$ solution of methylene blue (Aldrich, 85\% purity) was prepared in glycerol (Sigma Chemical Co., St. Louis, MO, Sigma grade). Reduction products were not among the dye impurities, as confirmed by electrohydrodynamic mass spectrometry [13]. The solution was not degassed prior to use. Data were acquired for 15-20 minutes, but only averaged over a 5-minute interval, as described in Results and Discussion. Occasionally, large intensity excursions were evident, attributable to the bursting of bubbles in the sample in vacuum. These scans were omitted, and averaging was extended to include a total of 5 minutes of acquisition time. Error bars represent the standard deviations of data from at least three fresh sample loadings.

\section{Results and Discussion}

The beam-induced reduction of methylene blue has been studied extensively $[14,16-26]$. For the purposes of this discussion, only the 1-hydrogen atom reduction product will be considered, although 2-hydrogen atom reduction can also be extensive. The extent of reduction can be quantitated using a relative enrichment factor, $E_{t}$ :

$$
E_{t}=\frac{i_{m}-i_{c}}{i_{c}}
$$

where subscript $\mathbf{t}$ denotes the time of the measurement (relative to the start of bombardment), $i_{m}$ is the measured peak intensity at $m / z 285\left([\mathrm{M}+1]^{+}\right.$ion), and $i_{\text {. }}$ is the corresponding calculated peak intensity based on natural isotopic abundances for $\mathrm{M}^{+}$. As background contributions increase (i,e, decreasing signal-to-background ratio at long $t$ due to sample depletion [16, $27])$, the value of $E_{1}$ will approach a flux-independent steady state. Visentini et al. [26] have shown that these effects can be neglected only if the signal-to-background $(S / B)$ ratio is at least $30: 1$.

In spectra of $15 \mathrm{mM}$ methylene blue in glycerol, we observed an initial rise-time of 1-2 minutes in the value of $E_{t}$, followed by a plateau of at least 5 minutes, then a sloping region as $S / B$ (using the signal from [M -3$]^{+}$at $m / z 281$ as a measure of background) fell below 30:1 (Figure 3 is typical). Accordingly, an average value, $\overline{\mathrm{E}}$, was determined by averaging over a 5 minute period usually beginning 2 minutes after initiation of bombardment. This procedure generally limited data averaged to the plateau region, and included the

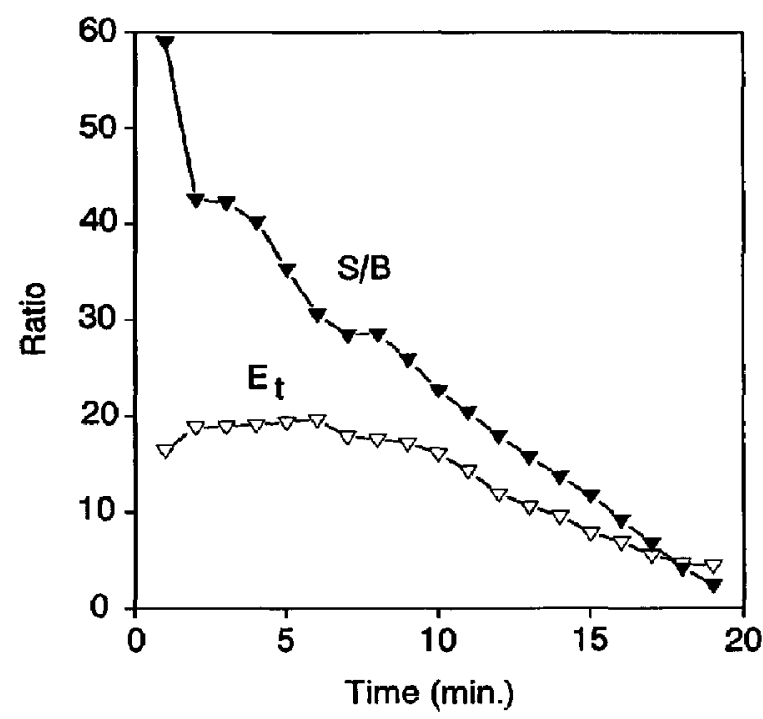

Figure 3. Time dependence of enrichment, $E_{t}$ of $[M+1]^{+}$(see text) $(\nabla)$ and signal-to-background ratio of $\mathrm{M}^{+}(\nabla)$ for hew FAB gun elertrodes with settings of $8 \mathrm{kV}$ and $1.0 \mathrm{~mA}$.

maximum $\mathrm{E}_{\mathrm{t}}$ value (excluding outliers due to bubbles, see above).

Figure 4 shows the dependence of $\overline{\mathrm{E}}$ on measured flux from the cesium ion gun. Flux is reported both in conventional units $\left(\mu \mathrm{A} \mathrm{cm} \mathrm{cm}^{-2}\right)$ and in particles $\mathrm{s}^{-1}$ $\mathrm{cm}^{2}$, the latter units being more appropriate for a

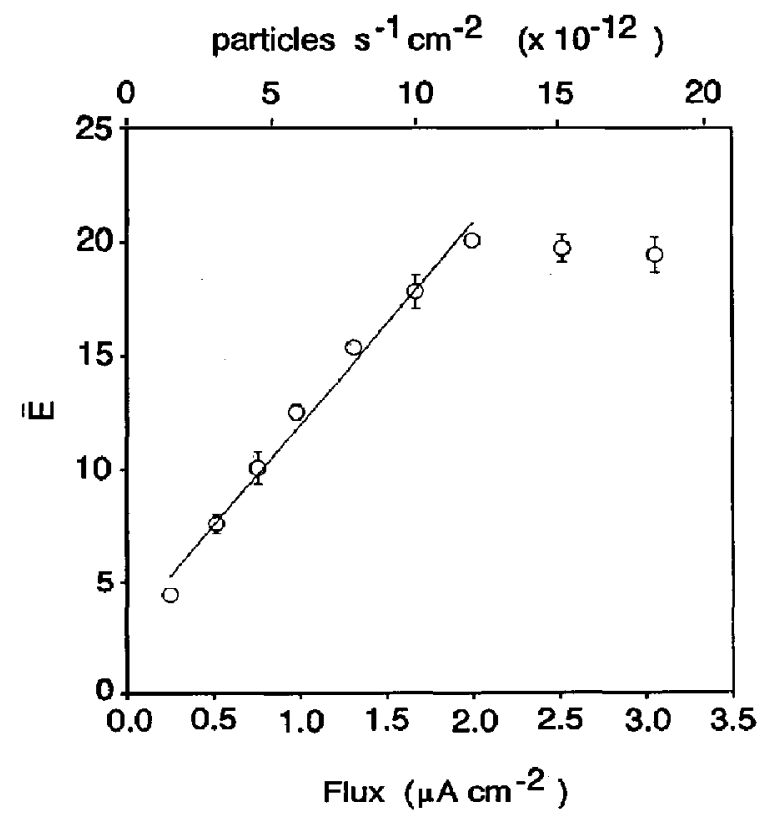

Figure 4. Average enrichment, $\overline{\mathrm{E}}$, of $[M+1]^{+}$(sce text) of methylene blue versus flux from the cesium ion gun. Line is least squares fit to the first seven data points. 
neutral FAB beam. (For LSIMS data, the two units are directly convertible: $1.00 \mu \mathrm{A} \mathrm{cm} \mathrm{cm}^{-2}=6.25 \times 10^{12}$ particles $\mathrm{s}^{-1} \mathrm{~cm}^{-2}$.) Below $1.16 \times 10^{13}$ particles $\mathrm{s}^{-1} \mathrm{~cm}^{-2}$, the curve is linear, giving a least squares fit to the following equation:

$$
\overline{\mathrm{E}}=\left(1.43 \times 10^{-12}\right) \times(\text { flux })+2.92 ;\left(\mathrm{R}^{2}=0.992\right)
$$

Above $1.16 \times 10^{13}$ particles $\mathrm{s}^{-1} \mathrm{~cm}^{-2}, \overline{\mathrm{E}}$ levels off. Visentini et al. [26] observed similar saturation at high flux. The detailed reasons for this saturation are under study. Its significance, in the context of the present study, is the (unsurprising) observation that applicability of a given flux calibration system is limited.

Figure 5 shows $\overline{\mathrm{E}}$ values measured with the $\mathrm{FAB}$ gun under various operating conditions. During the course of this study, the FAB gun electrodes had to be cleaned and ultimately replaced with new ones. We were fortunate to record the reduction of methylene blue during each stage. The plots of Figure 5 clearly show that the performance of the gun depends upon the condition of the electrodes within the gun. Alexander and Hogg [11] noted a similar effect: as the condition of their electrodes deteriorated, it was "possible for a change in secondary ion yield to be observed for apparently identical gun conditions." This deterioration increased the gas load required to sustain a discharge within the gun at given settings (Figure 6), thus decreasing the efficiency of primary beam production. Eventually, the electrodes became so worn that the gun failed, requiring that the electrodes be replaced. Figure 5 makes clear that during the lifetime of the gun, its output will vary, even if the emission current and nominal energy indicated on the power supply are nominally invariant. The changes are substantial. In

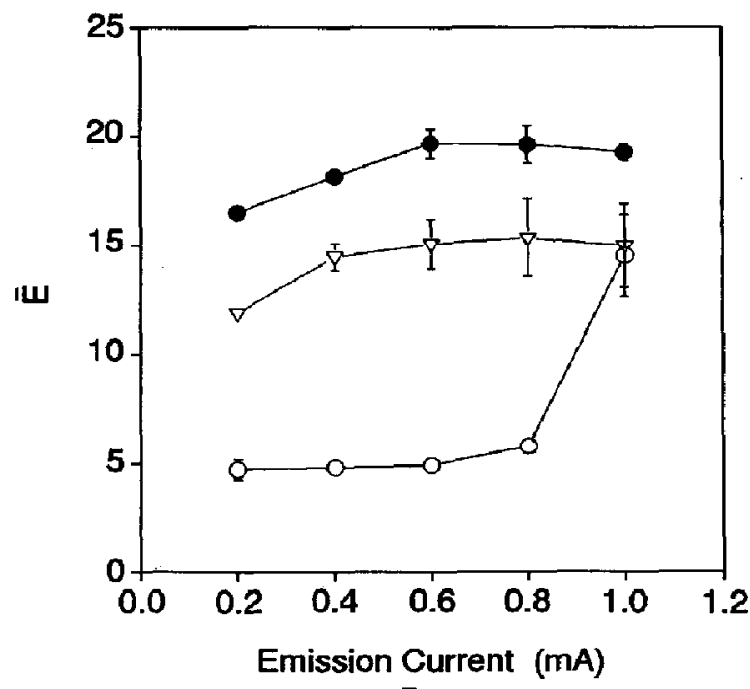

Figure 5. Average enrichment, $\overline{\mathrm{E}}$, of $[\mathrm{M}+1]^{+}$(see text) of methylene blue versus emission current from FAB gun with new $(O)$, cleaned $(\nabla)$, and dirty $(O)$ electrodes.

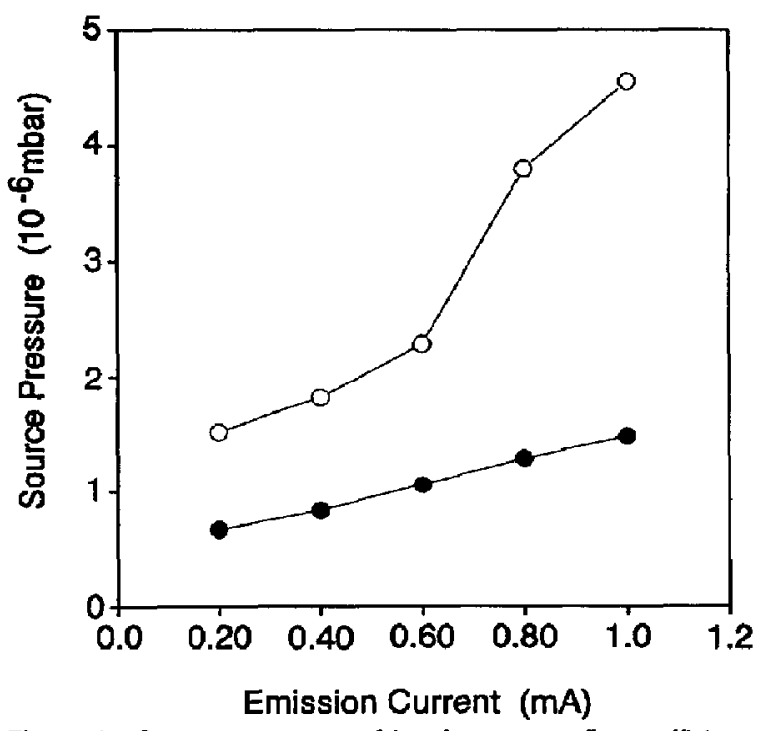

Figure 6. Source pressure resulting from xenon flow sufficient to sustain different emission currents with dirty $(O)$ and new (O) electrodes.

light of the fact that flux has a bigger effect on $\overline{\mathrm{F}}$ than does primary beam energy [13] [e.g., for 15 replicate $\overline{\mathrm{E}}$ values obtained at four different $\mathrm{Cs}^{+}$primary ion beam energies over the range $6-10 \mathrm{keV}$, the correlation coefficient $\left(R^{2}\right)$ between $\overline{\mathrm{E}}$ and energy is only 0.080 , compared with $R^{2}=0.992$ for the data of eq 2; energy has little effect on $\overline{\mathrm{E}}$ over this range], we attribute the performance deterioration primarily to a change in flux. Given the standard practice of citing emission current drawn by the FAB gun, it is obvious that reproducibility of $F A B$ results will depend upon the physical condition of the gun. Flux calibration using a parameter like $\overline{\mathrm{E}}$ should substantially improve this situation.

From the average enrichment values of Figure 5 and the equation given for the data in Figure 4, a corresponding flux can be calculated for the FAB gun (Table 1). The flux values so calculated fall near the lower end of the range of estimates reported by Ligon and Dorn [21] $\left(1.9-120 \times 10^{12}\right.$ particles $\mathrm{s}^{-1} \mathrm{~cm}^{-2}$, operating at 7 $\mathrm{kV}$ and $0.80 \mathrm{~mA}$ ). However, since saturation of the reduction effect allowed estimation of only a lower limit in high flux cases, the results of Table 1 are not necessarily incompatible with the upper limit reported by Ligon and Dorn [21].

To estimate the equivalent current emanating from the FAB gun (for comparison with the data of Alexander and Hogg [11], the bearr's lateral profile was assessed by viewing beam-induced luminescence on a CsI-coated target larger than the normal probe tip. The image consisted of a bright central region of fairly uniform intensity, surrounded by a diffuse ring of much lower intensity, as has been observed elsewhere [15]. At the short gun-target distance employed ( $\sim 4$ 
Table 1. Important FAB gun parameters with different electrodes ${ }^{a}$

\begin{tabular}{|c|c|c|c|c|c|c|c|}
\hline \multirow[b]{2}{*}{$\begin{array}{c}\text { Emission } \\
\text { Current } \\
\text { (mA) }\end{array}$} & \multicolumn{3}{|c|}{ Dirty } & \multirow{2}{*}{ 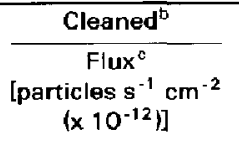 } & \multirow[b]{2}{*}{$\begin{array}{l}\text { Flux }{ }^{\mathrm{c}} \\
\text { [particles } \mathrm{s}^{-1} \mathrm{~cm}^{-2} \\
\left.\left(\times 10^{-12}\right)\right]\end{array}$} & \multirow{2}{*}{$\begin{array}{l}\text { New } \\
\text { Area } \\
\left(\mathrm{cm}^{2}\right)\end{array}$} & \multirow[b]{2}{*}{$\begin{array}{c}\text { Current } \\
{\text { [particles } \mathrm{s}^{-1}}_{\left.\left(\mathrm{x} 10^{-12}\right)\right]}\end{array}$} \\
\hline & $\begin{array}{c}\text { Flux }^{\mathrm{c}} \\
\text { [particles } \mathrm{s}^{-1} \mathrm{~cm}^{-2} \\
\left.\left(\times 10^{-12}\right)\right]\end{array}$ & $\begin{array}{l}\text { Area } \\
\left(\mathrm{cm}^{2}\right)\end{array}$ & $\begin{array}{c}\text { Current } \\
\text { [particles } \mathbf{s}^{-1} \\
\left.\left(\times 10^{-12}\right)\right]\end{array}$ & & & & \\
\hline 1.00 & $8.12 \pm 1.06$ & $0.28 \pm 0.02$ & $2.3 \pm 0.26$ & $8.44 \pm 1.06$ & $\geq 11.6 \pm 0.2$ & $0.28 \pm 0.02$ & $\geq 3.2 \pm 0.3$ \\
\hline 0.80 & $2.00 \pm 0.06$ & $0.28 \pm 0.02$ & $0.56 \pm 0.03$ & $8.69 \pm 1.00$ & $\geq 11.6 \pm 0.5$ & $0.20 \pm 0.02$ & $\geq 2.3 \pm 0.2$ \\
\hline 0.60 & $1.38 \pm 0.06$ & $0.24 \pm 0.02$ & $0.33 \pm 0.02$ & $8.50 \pm 0.60$ & $\geq 11.6 \pm 0.4$ & $0.16 \pm 0.02$ & $\geq 1.9 \pm 0.1$ \\
\hline 0.40 & $1.31 \pm 0.06$ & $0.13 \pm 0.02$ & $0.17 \pm 0.02$ & $8.06 \pm 0.38$ & $10.6 \pm 0.2$ & $0.11 \pm 0.02$ & $1.2 \pm 0.1$ \\
\hline 0.20 & $1.25 \pm 0.12$ & $0.07 \pm 0.01$ & $0.09 \pm 0.01$ & $6.25 \pm 0.12$ & $9.50 \pm 0.06$ & $0.07 \pm 0.01$ & $0.66 \pm 0.1$ \\
\hline
\end{tabular}

Estialated uncer lainlies are standard deviations as determined by propagation of errors analysis.

Beam area not available for cleaned electrodes.

To convert to $\mu \mathrm{A} \mathrm{cm} \mathrm{cm}^{-2}: 1.00 \mu \mathrm{A} \mathrm{cm} \mathrm{m}^{-2}=6.25 \times 10^{12}$ particles $\mathrm{s}^{-1} \mathrm{~cm}^{-2}$.

$\mathrm{cm}$ ), the observed solid angle of beam divergence (estimated from the central bright region) was small $\left(\sim 10^{\circ}\right)$, accounting for the apparent uniformity of illumination within the bright region. The diameter of the central region increased with emission current, probably due to increased scattering at the higher pressures needed to maintain higher currents (Figure 6). Even at the lowest emission currents, the bright region encompassed the entire normal probe tip. Thus, the flux values of Table 1 may be considered to pertain throughout the bright area. To establish an estimate of the equivalent current, then, the area of the bright region was multiplied times the flux. This approach ignores the low intensity portion of the beam at the periphery (thus excluding some contributions), but probably overestimates contributions in the bright center by assuming uniform illumination rather than a continuous decrease in intensity as a function of lateral (off-axis) displacement. Results from this calculation are summarized in Table 1 (the old electrodes failed before beam diameters and source pressures under "cleaned" conditions could be recorded).

While equivalent currents in Table 1 are reasonable, even the highest values fall below Alexander and Hogg's [11] estimated "neutral current equivalent" (6.6 $\mu \mathrm{A}$ or $4.1 \times 10^{13}$ particles $\mathrm{s}^{-1} \mathrm{~cm}^{-2}$, operating at $7 \mathrm{kV}$ and $1.0 \mathrm{~mA}$ ). Direct comparison is difficult, in part because there is no way to determine the condition of electrodes used in other labs. The shortfall may result in part from saturation of the reduction effect under highest flux conditions used here. The virtue of chemical-based flux calibration like that proposed is that it allows comparison of operating conditions, even in the face of such uncertainties.

It can be seen from data presented in Table 1 that new electrodes provide higher fluxes and equivalent currents than do old electrodes, dirty or cleaned. Figure 6 shows that new electrodes require less gas to sustain a discharge under the given operating conditions than the dirty, old electrodes. The old electrodes were in use over a 5-year period. During that time, the electrodes were cleaned approximately every $10-15$ months. Shortly after the last cleaning, the electrodes failed completely and were replaced with the new electrodes. These new electrodes had been in service for 5 months (approximately 75 hours of actual operation) when these data were acquired. An investigation into the aging process of these electrodes is continuing.

\section{Conclusions}

This study clearly shows that the performance of a saddle field atom gun changes as the condition of the electrodes deteriorates. This decline decreases the flux emerging from the gun. These changes are not reflected in readings from the power supply to the FAB gun and can drastically affect spectral reproducibility. The flux can be calibrated by using a parameter such as beam-induced reduction. The reduction of methylene blue provides flux calibration through $1.16 \times 10^{13}$ particles $\mathrm{s}^{-1} \mathrm{~cm}^{-2}$. Another compound or method must be found to calibrate flux at higher levels. Critical comparisons of FAB results should be facilitated by citing flux (or a parameter like $\overline{\mathrm{E}}$ ) rather than emission current from the power supply.

\section{Acknowledgments}

This work was supported by the National Science Foundation under grant no. CHE-8822787. The UTK Chemistry Mass Spectrometry Center is funded by the Science Alliance, a State of Tennessee Center of Excellence. The NSF Chemical Instrumentation Program also contributed to the acquisition of the ZAB-EQ (grant no. CHE-8609251). We thank Dr. P. J. Todd for helpful discussions and assistance with the cesium ion gun.

\section{References}

1. Barber, M.; Bordoli, R. S.; Sedgwick, R. D.; Tyler, A. N. J. Chem. Soc. Chem. Comnun. 1981, 325.

2. Aberth, W.; Straub, K. M.; Burlingame, A. L. Anal. Chem. 1982, 54, 2029.

3. McEwen, C. N. Anal. Chem. 1983, 55, 967.

4. Fenselau, C.; Cotter, R. J. Chem. Rev. 1987, 87, 50.

5. Detter, L. D.; Hand, O. W.; Cooks, R. G.; Walton, R. A. Mass Spectrom. Rev. 1988, 7, 465.

6. Burlingame, A. L.; Baillie, T. A.; Russell, D. H. Anal. Chem. 1992, 64, 467R.

7. Williams, D. H.; Findeis, A. F.; Naylor, S.; Gibson, B. W. J. Am. Chent. Soc. 1987, 109, 1980. 
8. Derwa, F.; De Pauw, E.; Natalis, P. Org. Mass Spectrom. 1991, 26,117 .

9. Takayama, M.; Fukai, T.; Nomura, T. Int. J. Mass Spectrom. Ion Processes 1989, 89, R1.

10. Ligon, W. V. Int. J. Mass Spectrom. Ion Processes 1982, 41, 205.

11. Alexander, A. J.; Hogg, A. M. Int. I. Mass Spectrom. Ion Processes 1986, 69, 297.

12. De Pauw, E.; Pelzer, G.; Marien, J. Org. Mass Spectrom. 1985, 20,693 .

13. Reynolds, J. D.; Cook, K. D. J. Am, Soc. Mass Spectrom. 1990, 1, 149.

14. Brown, S. M.; Busch, K. L. Rapid Commun. Mass Spectrom. 1988, 2, 256.

15. Falick, A. M.; Wang, G. H.; Walls, F. C. Anal. Chem. 1986, 58, 1308 ,

16. Gale, P. J.; Bentz, B. L.; Chait, B. T.; Field, F. H.; Cotter, R. I. Anal. Chem. 1986, 58, 1070.

17. McEwen, C. N.; Layton, S. F.; Taylor, S. K. Anal. Chem. 1977, $49,922$.
18. Scheifers, S. M.; Verma, S.; Cooks, R. G. Anal. Chem. 1983, 55, 2260.

19. Pannell, L. K.; Sokoloski, E. A.; Fales, H. M.; Tate, R. L. Anal. Chem. 1985, 57, 1060.

20. Burinsky, D. J.; Dilliplane, R. L.; DiDonato, G. C.; Busch, K. L. Org. Mass Spectrom. 1988, 23, 231.

21. Ligon, Jr. W. V.; Dorn, S. B. Int. J. Mass Spectrom Ion Processes $1984,57,75$.

22. Bentz, B. L.; Gale, P. J. Int. J. Mass Spectrom. Ion Processes 1987, 78, 115.

23. Mathias, A.; Williams, A. E.; Games, D. E.; Jackson, A. H. Org. Mass Spectrom. 1976, 11, 266.

24. Kazakoff, C. $W_{v}$ Rye, R. T. B. Org. Mass Spectrom. 1991, 26, 154.

25. Kyranos, J. N.; Vouros, P. Biomed. Environ. Mass Spectrom. 1990, 19, 628.

26. Visentini, J.; Zidarov, D.; Allard, M.; Bertrand, M. J. J. Am. Soc. Mass Spectrom. 1993, 4, 482.

27. Field, F. H. J. Phys. Chem. 1982, 86, 5115. 